\title{
ESPAÇO GEOGRÁFICO, TERRITÓRIO USADO E LUGAR: ENSAIO SOBRE O PENSAMENTO DE MILTON SANTOS
}

\author{
Thiago Augusto Nogueira de Queiroz ${ }^{*}$ \\ * Mestre em Geografia - UFRN, Professor de Geografia - IFRN. E-mail: queiroztan@gmail.com
}

Recebido em 12/2014. Aceito para publicação em 05/2015.

Versão online publicada em 13/01/2016 (http://seer.ufrgs.br/paraonde)

\begin{abstract}
Resumo: Este artigo originou-se das discussões oriundas da disciplina Geografia Humana, oferecida ao curso de História. $\mathrm{O}$ espaço não é o conceito chave em todas as correntes do pensamento geográfico. A corrente da Geografia Tradicional, influenciada pelo positivismo, historicismo e neokantismo, tem o território, a paisagem e a região como principais conceitos. A corrente da Geografia Humanista, com base no existencialismo, foca o conceito de lugar, entendido como espaço vivido. As correntes que colocam o espaço como palavra-chave são a Geografia Quantitativa, com influências do neopositivismo, e a Geografia Crítica, alicerçada no materialismo histórico. Na primeira corrente, o espaço é compreendido de forma ideal, enquanto, na segunda, o espaço é entendido em sua materialidade, com objetivações e subjetivações. A corrente Crítica teve uma importante contribuição do geógrafo brasileiro Milton Santos, influenciado pelo materialismo histórico, pelo estruturalismo e pelo existencialismo. Nessa perspectiva, este artigo tem como objetivo mostrar a contribuição do pensamento e da obra do geógrafo Milton Santos para a Geografia Crítica e para a teoria social crítica, focando os conceitos de espaço geográfico, território usado e lugar, que são as três escalas conceituais para compreender a totalidade socioespacial. Para tal fim, fizemos uma revisão bibliográfica do autor, e sobre o autor, perpassando suas principais obras. Para o autor, "espaço" é uma instância social, assim como a política, a economia e a cultura. 0 espaço, no atual período histórico, caracteriza-se pela materialização do meio técnico-científico-informacional, expressão geográfica da globalização. Assim, esse conceito deve ser analisado a partir de três escalas da totalidade: o mundo, a formação socioespacial e o cotidiano. A totalidade mundo é o espaço geográfico formado por sistemas de objetos (fixos e configurações espaciais) e sistemas de ações (fluxos e dinâmicas sociais). 0 espaço geográfico é, portanto, constituído por formas (espaços de produção, de distribuição, de troca, de consumo, de circulação) e por conteúdos (estruturas, processos e funções). A totalidade da formação socioespacial é o território usado, composto pela configuração territorial (as infraestruturas e o meio ecológico) e a dinâmica territorial (uso do território pelos agentes - firmas, instituições e pessoas). É no uso do território pelos diferentes agentes que ocorre a dialética entre o externo e o interno, o novo e o velho, o Estado e o mercado. Por fim, o autor destaca a totalidade do lugar, a dimensão geográfica do cotidiano, onde ocorre a dialética entre circuito superior e circuito inferior, verticalidades e horizontalidades, racionalidades e contrarracionalidades, solidariedade organizacional e solidariedade orgânica. O lugar é, nesse sentido, a força para enfrentar a globalização como fábula e como perversidade, produzida pelas redes; e construir uma globalização como possibilidade. Palavras-chave: espaço geográfico, território usado, lugar, totalidade, Milton Santos.
\end{abstract}

\section{Introdução}

Partindo de uma perspectiva crítica, com base filosófica no materialismo histórico e no método dialético, o objeto de estudo da Geografia é o espaço geográfico. Este é analisado por meio dos conceitos socioespaciais que o constitui, a saber - paisagem, rede, território e lugar. Porém, o espaço geográfico não é um conceito restrito a uma disciplina específica, no caso a Geografia, sendo utilizado e debatido por filósofos, sociólogos, economistas, cientistas políticos e antropólogos (CORRÊA, 1995).

Entre as correntes da ciência geográfica - Geografia Tradicional ou Clássica, Geografia Quantitativa ou Teorética, Geografia Humanista ou Cultural Renovada e Geografia Crítica ou Radical - não há um consentimento sobre o conceito de espaço devido às diferentes matrizes filosóficas e aos diferentes métodos de abordagem de cada uma das correntes (CORRÊA, 1995).

A Geografia Tradicional foi hegemônica entre 1870 - quando foram institucionalizados os primeiros cursos superiores de Geografia - e 1950 - quando a Geografia passa por um processo de renovação filosófica e metodológica. A Geografia Tradicional se caracterizava pelas matrizes filosóficas do positivismo, historicismo e neokantismo. E tinha por base os métodos indutivo e dedutivo.

A matriz filosófica positivista era típica da Escola Alemã de Geografia, a Escola determinista, que tinha como principal pensador Friederich Ratzel, como também, o principal conceito utilizado era o território. A matriz historicista caracterizava a Escola Francesa, po- 
ssibilista, que tinha como principal pensador Vidal De La Blache, e a paisagem como conceito mais significativo. Por fim, o neokantismo era a matriz predominante na Escola Anglo-Saxônica, o regionalismo, encabeçado por Richard Hartshorne, e que tinha como principal conceito a região.

A primeira corrente de renovação filosófica e metodológica da Geografia foi a Quantitativa. Esta corrente teve sua hegemonia entre as décadas de $1950 \mathrm{e}$ 1970, tecendo uma crítica à falta de utilidade e pragmatismo da Geografia Tradicional. Caracteriza-se, também, pela matriz filosófica do neopositivismo e pelo método hipotético-dedutivo. A Geografia Quantitativa definiu o espaço como o conceito chave da Geografia, um espaço absoluto, isotópico, matricial, utilizado para a construção de sistemas e modelos aplicados ao planejamento e à organização do espaço.

A segunda corrente de renovação da Geografia foi a Crítica, que foi hegemônica entre as décadas de 1970 e 1990, enfatizando a crítica ao comprometimento da Geografia Tradicional e da Geografia Quantitativa com as classes sociais dominantes, com as ideologias burguesas. Essa corrente tem como principal base filosófica o materialismo histórico; e como método, a dialética. 0 espaço também é um conceito chave para a corrente Crítica.

Abre-se um parêntese para salientar que há também a corrente da Geografia Humanista, a terceira linha de renovação da ciência geográfica, que resgata alguns elementos da Geografia Tradicional e faz a crítica à falta de subjetividade nas correntes Quantitativa e Crítica. Essa corrente tem como principal base filosófica o existencialismo; e como método, a fenomenologia. 0 espaço, na corrente Humanista, não é o conceito chave, privilegiando-se o conceito de lugar, enquanto o espaço vivido, espaço simbólico, espaço cotidiano.

Retomando a corrente da Geografia Crítica, a partir do ponto de vista de Edward Soja, há pelo menos três variações desta (SOJA, 1993). A primeira iniciouse na tradição marxista anglo-saxônica, no qual tinha como objetivo acrescentar, à Geografia, os conceitos e categorias de análise criadas por Karl Marx e pelo marxismo, seguindo rigidamente a filosofia do materialismo histórico (e geográfico) e o método dialético. Daí a denominação de Geografia Radical, à forma pela qual foi alcunhada a corrente Crítica nos Estados Unidos.

A segunda variação da Geografia Crítica iniciou-se na tradição marxista da França, que tinha o objetivo de acrescentar, ao marxismo, os conceitos e categorias da Geografia, seguindo o materialismo histórico e geográfico de forma flexível, com influências das correntes filosóficas do estruturalismo - tendo Louis Althusser como principal pensador - e do existencialismo - sendo Jean Paul Sartre o principal filósofo. Essa variação também é denominada de neomarxismo.

A partir da segunda, origina-se a terceira variação da Geografia Crítica, que tentou construir uma Geogra- fia a partir do Terceiro Mundo, dos países subdesenvolvidos, dos países pobres, seguindo o neomarxismo francês, sendo influenciado também pelo estruturalismo e pelo existencialismo. Nesse contexto, destacouse o geógrafo brasileiro Milton Santos, que discutiu sobre a natureza do espaço geográfico no atual período e meio técnico-científico-informacional, a sociedade e o uso do território no Brasil, e a força do lugar para possibilitar outra globalização.

Nesse contexto da história do pensamento geográfico, este artigo tem como objetivo mostrar a contribuição do pensamento e da obra do geógrafo Milton Santos para a Geografia Crítica e para a teoria social crítica, focando os conceitos de espaço geográfico, território usado e lugar, que são as três escalas conceituais para compreender a totalidade socioespacial. Para tal fim, fizemos uma revisão bibliográfica do autor, e sobre o autor, perpassando suas principais obras.

\section{0 espaço geográfico: a totalidade do mundo}

O espaço geográfico (SANTOS, 1996) é diferente do espaço social (LEFEBVRE, 1974), porém este está inserido naquele. 0 espaço geográfico é concreto; não é abstrato; é a junção do espaço material com o espaço social. 0 espaço material é o espaço físico, ou seja, engloba o espaço natural e o espaço produto do trabalho humano. 0 espaço social é o espaço imaterial, embora dependa da materialidade para existir (SOUZA, 2013). O espaço social é o espaço das redes e das interações espaciais, dos territórios e das territorialidades, dos lugares e das representações sociais.

O espaço geográfico é definido por Milton Santos como um fato e um fator social. Ou seja, o espaço geográfico não seria somente um reflexo, um meio para a ação da sociedade. 0 espaço geográfico é, assim, um condicionado e um condicionador. Nesse sentido, o espaço geográfico é uma instância social como as demais - economia, política e cultura ou ideologia (ALTHUSSER, 1974) -, sendo uma instância ao mesmo tempo subordinada e subordinadora (SANTOS, 1978).

Milton Santos também discutiu sobre a natureza do espaço geográfico. Inicialmente, o autor definiu sua natureza como sendo um conjunto de fixos e fluxos (SANTOS, 1978). Em um segundo momento, o autor definiu a natureza do espaço geográfico como sendo um conjunto de configurações espaciais e dinâmicas sociais (SANTOS, 1988). Por fim, o autor destaca que a natureza do espaço geográfico é um conjunto indissociável, complementar e contraditório de sistemas de objetos e sistemas de ações (SANTOS, 1996).

Diante desse contexto, observamos que, para Milton Santos, a natureza do espaço geográfico é a dialética entre a inércia e a dinâmica, entre o inerte e o prático, entre a forma e o conteúdo, entre o espaço material e o espaço social. Nessa perspectiva, o autor busca nas categorias de análise desenvolvidas por Jean Paul Sartre a natureza do espaço geográfico, que 
é a inércia-dinâmica, o prático-inerte, a forma-conteúdo (SARTRE, 2002 [1960]).

Essa dialética da natureza do espaço também é demonstrada por outros geógrafos, como David Harvey, que se ampara na matriz filosófica do materialismo histórico, e pertencente aos teóricos da Geografia Radical anglo-saxônica. Esse autor aponta o espaço como um conjunto de processos sociais e formas espaciais, ou seja, assim como Milton Santos, o britânico David Harvey afirma que o espaço é formado pela imaterialidade da dinâmica social e pela materialidade das infraestruturas do espaço (HARVEY, 1980).

Para Milton Santos, o espaço geográfico é uma totalidade e deveria ser analisado como tal. Para isso, o geógrafo brasileiro propôs a análise do espaço a partir da indissociabilidade e da holística entre forma e conteúdo - estrutura, processo e função (SANTOS, 1985). A forma é todo o espaço material visível, por exemplo, as moradias, as indústrias, os comércios, os serviços, as cidades, a rede urbana.

Cada forma tem seu conteúdo, que pode ser subdividido em estruturas, processos e funções. As estruturas são a natureza das formas, que podem ser econômicas - as firmas industriais, de comércios e de serviços -, políticas - as instituições - e culturais - as igrejas, os teatros, os cinemas, os espaços públicos e de lazer. As funções são as atividades - industriais, comerciais e residenciais - desempenhadas, pelos agentes, nessas formas. Estas também desempenham funções, pois, elas não são apenas produtos, condicionados e subordinados. As formas também são produtoras, condicionadoras e subordinadoras das ações sociais.

Os processos são os fluxos, a dinâmica, as ações, históricas e presentes, que se originam, são destinadas, ou ocorrem no interior de cada forma. Assim, os processos são originados das formas, como também, os processos dão origem às formas, por exemplo: o processo de centralização origina os centros das cidades; o processo de descentralização originam as novas centralidades das cidades; o processo de coesão originam as áreas especializadas; o processo de segregação socioespacial gera as áreas sociais, como os condomínios horizontais e verticais, os conjuntos habitacionais e as favelas nas cidades.

Além disso, a totalidade do espaço pode ser analisada a partir da integralidade entre os espaços das instâncias produtivas - espaços de produção, espaços de circulação, espaços de consumo - que formam os circuitos espaciais produtivos (SANTOS, 1986). Os espaços de produção são as áreas agrícolas, as áreas de mineração e as indústrias. Os espaços de circulação são as hidrovias, ferrovias, rodovias, aerovias, infovias, avenidas e ruas. Os espaços de consumo são as áreas agrícolas, as áreas extrativistas, as indústrias, os comércios, os serviços, como também, as residências.

Para além da discussão sobre o conceito de espaço geográfico, a natureza desse espaço e as suas partes da totalidade, Milton Santos também discute sobre as variáveis que caracterizam o espaço em cada período da história da humanidade. Nesse contexto, o autor divide a história do espaço geográfico em quatro períodos: natural, técnico, técnico-científico e técnicocientífico-informacional (SANTOS, 1996).

0 período natural é todo o período históricogeográfico anterior à Revolução Industrial, ou seja, anterior ao século XVIII. A partir da Revolução Industrial a técnica passa a ter autonomia, e passam a ter a qualidade de objetos técnicos e não apenas de técnica humana. Assim, só passa a existir um meio técnico, após a Revolução Industrial, quando o ser humano passa a produzir objetos técnicos, com autonomia de funcionamento, próteses humanas ao meio natural.

Com a Segunda Revolução Industrial, no século XIX, quando começam a surgir as primeiras disciplinas da ciência - Geografia, História, Sociologia, Antropologia, Economia política, Biologia, Química, Física -, os objetos técnicos também passam a ter uma nova variável, a ciência. Esta passa a desenvolver e ser desenvolvida por esses objetos técnicos, assim, o ser humano passa a vivenciar o período técnico-científico, o período da tecnociência.

No século XX, após a Segunda Guerra Mundial, ocorre a Terceira Revolução Industrial, que se desenvolve no contexto da Guerra Fria, com o avanço nas telecomunicações, e se consolida na década de 1990, com a criação da internet. Nesse contexto, os objetos técnicos dotados de ciência passam também conter informação. Assim, o ser humano se insere no período técnico-científico-informacional, que se materializa em um meio técnico-científico-informacional, a expressão geográfica da globalização, da modernização do campo e da cidade.

Portanto, no pensamento de Milton Santos, o espaço geográfico é uma instância social. A natureza desse espaço é a forma-conteúdo. A sua totalidade está presente na integração entre formas, estruturas, processos e funções, como também, na inseparabilidade entre produção, distribuição, troca e consumo. Esse espaço é caracterizado atualmente pelo período e meio técnico-científico-informacional. O espaço geográfico, enfim, é a totalidade do mundo, necessária para a compreensão de outras duas escalas da totalidade: a formação socioespacial e o cotidiano.

\section{0 território usado: a totalidade da formação so- cioespacial}

De acordo com Milton Santos, os marxistas enfatizaram os conceitos de modo de produção e de formação social. Porém, o geógrafo brasileiro alerta que não há uma formação social que também não seja espacial. Daí, o autor propõe enfatizar a estrutura espacial da sociedade, denominando, as particularidades do modo de produção capitalista, de formação socioespacial, ou seja, a formação social ocorre simultaneamente com a formação espacial. Assim, cada sociedade tem seu 
próprio espaço e sua própria formação socioespacial (SANTOS, 2005[1978]).

O Estado é a formação socioespacial. 0 Estado é constituído por: governo, povo, soberania e território. Este é, tradicionalmente, o espaço geográfico do Estado, que também é uma totalidade. Assim, define-se a segunda escala da totalidade: a primeira escala, a totalidade dos modos de produção ou do mundo, é o espaço geográfico; a segunda escala, a totalidade da formação socioespacial, é o Estado e seu território.

0 território, para Milton Santos, não é organizado somente pelo Estado, como também, não está restrito, para Milton Santos, à dimensão política do espaço, ou seja, não é apenas um espaço delimitado pelas relações de poder (SOUZA, 2013). Há também o uso e apropriação do território por outros agentes. 0 território engloba as relações de poder, assim como, as relações econômicas e simbólicas.

0 território nas obras de Milton Santos é, em grande parte, baseado no conceito de território de Claude Raffestin, geógrafo suíço influenciado pela Escola Francesa de Geografia, ancorado no estruturalismo e no materialismo histórico. Esse autor entende o território como um conjunto de sistemas de objetos e sistemas de ações. Como também, o território é formado pelas diferentes territorialidades, uso e apropriação do espaço, dos diferentes agentes. Para ele o território também é formado por superfícies (as estruturas econômicas, políticas e culturais), por linhas (as redes) e por pontos (os lugares) (RAFFESTIN, 1993). A relação entre território, redes e lugares também é discutida por Milton Santos.

Nesse contexto, para Milton Santos, não é o território em si a categoria de análise social, mas, o território usado (SANTOS, 1994), sinônimo de espaço geográfico (SANTOS \& SILVEIRA, 2001). Milton Santos dá ao território um status de escala geográfica. Nesse sentido, o território usado é simultaneamente material e social, composto por uma dialética, como o espaço geográfico. 0 território-forma é o espaço material e o território usado é o espaço material mais o espaço social. 0 território usado é constituído pelo território forma - espaço geográfico do Estado - e seu uso, apropriação, produção, ordenamento e organização pelos diversos agentes que o compõem: as firmas, as instituições - incluindo o próprio Estado - e as pessoas.

As firmas são representadas pelas empresas privadas, sociedades anônimas, sociedade de economia mista, sociedades limitadas que têm a função de produção, distribuição, troca e consumo de mercadorias e serviços. As instituições são os órgãos estatais, as associações, as organizações filantrópicas e as organizações não governamentais, que produzem normas, ordens e informações. As pessoas são os seres humanos em geral, a população ou parte dela que compõem as firmas e as instituições (SANTOS, 1985).

As firmas, em alguns casos, também se tornam instituições quando impõem suas normas, suas ordens e suas informações à sociedade. As instituições também podem atuar como firmas, no caso das empresas estatais, ou serem compostas por firmas. As pessoas podem também atuar como firmas nos processos de produção, distribuição, troca e consumo, além de agirem como instituição, quando exercem sua cidadania no cotidiano. Todos esses agentes usam as infraestruturas. Estas são constituídas pelo espaço físico natural - o meio ecológico - e pelo espaço físico humanizado - o meio construído, os sistemas de engenharia.

Esses agentes do espaço - firmas, instituições e pessoas - também produzem a dialética do território. Esta dialética ocorre entre o externo e o interno, o novo e velho, o mercado e o Estado (SANTOS, 1988). Nesse sentido, o território é formado por: agentes externos e internos; novas e velhas infraestruturas e agentes, que produzem as rugosidades do território; e pela cooperação e conflito entre o mercado, que geralmente é o elemento externo e novo, e o Estado, que na maioria das vezes atua como o elemento interno e velho.

Esse conflito entre o mercado e o Estado foi modificado ao longo do capitalismo. A doutrina política do liberalismo, apoiado na internacionalização econômica e no meio técnico, ganhou força após a Revolução Industrial, pregando a não intervenção do Estado no mercado. A doutrina política do keynesianismo, o Estado de bem estar social, apoiado na mundialização econômica e no meio técnico-científico, ganhou força após a crise econômica global de 1929, difundindo a ideia de um Estado interventor no mercado.

No pós Segunda Guerra, surge a doutrina política do neoliberalismo, que ganhou força com a crise econômica global de 1973, e consolidou-se na década de 1990 com o fim da URSS e do bloco geopolítico do socialismo. Esse neoliberalismo está atrelado à globalização econômica e ao meio técnico-científico-informacional, que facilitam sua difusão. Tal doutrina anuncia a intervenção mínima - e não ausência - do Estado no mercado, acompanhado de privatizações, terceirizações e descentralizações do papel do Estado.

A crise econômica global de 2008 colocou em cheque a doutrina do neoliberalismo. No atual cenário mundial da dialética entre o mercado e o Estado, observa-se o conflito entre a doutrina neoliberal - mais mercado e menos Estado - e a doutrina keynesiana mais Estado e menos mercado. Será que também poderíamos afirmar que estamos vivenciando um pós-neoliberalismo - um estágio híbrido entre o neoliberalismo e o keynesianismo? Não é nosso intuito discutir tal fato neste artigo, porém deixaremos a instiga para uma discussão posterior.

O espaço geográfico atual está inserido no período técnico-científico-informacional, e sua materialização, nos territórios, é o meio técnico-científico-informacional. Porém, este meio não se materializa no território em totalidade, algumas regiões e lugares são selecionados, usadas e apropriadas pelos agentes modernizantes do espaço, as variáveis da globalização. 
O período e o meio natural predominaram no Brasil desde a chegada dos portugueses ao território, em 1500 , até o século XVIII. O período técnico caracteriza-se, no Brasil, pelos "arquipélagos" econômicos, ou seja, as diversas atividades econômicas espraiadas pelo território e que pouco se comunicavam entre si. O período técnico-científico, vai se caracterizar no Brasil pela circulação mecanizada e pelos primeiros surtos industriais, além do surgimento da ideia da integração nacional. 0 período técnico-científico-informacional passou a se materializar, no Brasil, a partir da década de 1970, com o desenvolvimento tecnológico e ampliação dos meios de transporte, comunicação e informação.

0 advento do período técnico-científico-informacional, através do conhecimento e da informação, provocou uma renovação da materialidade do território. Como também, uma reorganização produtiva, coexistindo novos e velhos circuitos espaciais produtivos e círculos de cooperação. Também houve um aumento dos fluxos, crescimento do sistema financeiro, redistribuição da população, aumento do consumo e dos níveis de vida. Considerando os aspectos técnicos, científicos e informacionais o território se divide regionalmente em: Região Concentrada, Nordeste; Central; e Amazônia (SANTOS \& SILVERA, 2001).

\section{0 lugar: a totalidade do cotidiano}

O lugar não está restrito, para Milton Santos, à dimensão cultural ou simbólica do espaço, ou seja, não é apenas uma relação social imaterial (SOUZA, 2013). Nem o lugar, para esse autor, é entendido apenas como o espaço vivido (TUAN, 1983). 0 lugar, assim como o território, é simultaneamente uma materialidade e uma imaterialidade; é vivido e percebido; é a dimensão espacial do cotidiano (SANTOS, 1996). O lugar, portanto, é a escala da totalidade do cotidiano. 0 lugar-mundo deve ser entendido a partir da relação entre o espaço geográfico, o território usado e o lugar.

A globalização tem uma face como fábula - a globalização que nos mostram ou como querem que a compreendamos -, uma face como perversidade - a globalização como realmente ela é -, ambas são faces da globalização produzida pelos agentes hegemônicos do período técnico-científico-informacional. Porém, o lugar é a força dos agentes não hegemônicos, das pessoas em seus cotidianos, para criar uma outra globalização - a globalização como possibilidade, a globalização vista do lado de cá (SANTOS, 2000).

No lugar, ocorre a dialética das escalas no território: entre as redes e os lugares, entre os lugares em redes e os lugares contíguos, entre o local e o global. No lugar ocorre a dialética entre as verticalidades - relações verticais, de hierarquia, externas ao lugar, geralmente novas ao lugar, e geralmente demandadas pelo mercado ou pelo Estado - e as horizontalidades - relações horizontais, de vizinhança e proximidade, internas ao lugar, geralmente velhas e demandadas pelo
Estado e pelas pessoas que vivem no lugar.

Milton Santos busca em Jean-Paul Sartre a interligação entre essas relações e os aconteceres. As relações de verticalidades fazem parte dos aconteceres hierárquicos, produzidos pelos agentes hegemônicos, enquanto as horizontalidades fazem parte das formas de acontecer complementares e homólogas, que são produzidas, respectivamente, pelos agentes hegemonizados e não hegemônicos (SANTOS, 1996).

0 geógrafo brasileiro também busca em Max Weber para associar essas relações com as racionalidades (WEBER, 1991 [1920]). As verticalidades produzem os espaços de racionalidade, que são espaços de fluxos, de alguns, luminosos, fluidos, velozes, densos, que mandam, e contraditoriamente atendem às necessidades dos agentes da globalização e do neoliberalismo. As horizontalidades são criadoras dos espaços de racionalidade paralela e de contra racionalidade, que são os espaços de todos, opacos, viscosos, lentos, rarefeitos, que obedecem e contraditoriamente tornam-se contrários às vertentes da globalização e do neoliberalismo.

Por fim, o autor busca em Emile Durkheim a compreensão do cotidiano, dando um novo sentido aos conceitos de solidariedade mecânica e solidariedade orgânica (DURKHEIM, 1978 [1897]). Assim, há a dialética entre a solidariedade organizacional - das firmas e das instituições atreladas às verticalidades, aconteceres hierárquicos e racionalidades da globalização - e a solidariedade orgânica - das pessoas atreladas às horizontalidades, aconteceres homólogos e contra racionalidades à globalização.

A ideia dos circuitos espaciais produtivos, desenvolvida por Milton Santos, tem origem na obra de Karl Marx, que desenvolveu a ideia que o processo de circulação em sua totalidade é formado pela produção, distribuição, troca e consumo (MARX, 2011 [1857]). Nesse sentido Milton Santos propõe que os circuitos espaciais produtivos são os espaços de produção, de circulação e de consumo de um determinado produto (SANTOS, 1986). Esses circuitos espaciais produtivos são analiticamente divididos em circuito superior e circuito inferior (SANTOS, 1979).

O circuito superior é formado por agentes e elementos que utilizam alto grau de tecnologia, capital e organização, produzindo verticalidades, racionalidades e solidariedades organizacionais. 0 circuito inferior é formado por agentes e elementos que utilizam baixo nível de tecnologia, capital e organização, produzindo horizontalidades, contra racionalidades e solidariedades orgânicas. Os dois circuitos são originados de um mesmo processo: a modernização tecnológica do período técnico-científico-informacional. Por isso, não há um dualismo e sim uma bipolarização da economia espacial.

Nossas pesquisas mostraram o lugar-mundo dos agentes que trabalham e obtêm a renda necessária para sobreviver a partir das feiras livres, dos mercados 
públicos e da Ceasa-RN, na cidade de Natal, capital do estado federado do Rio Grande do Norte (QUEIROZ, 2011; QUEIROZ \& AZEVEDO, 2012; QUEIROZ \& AZEVEDO, 2013; QUEIROZ, 2014).

As feiras livres e os mercados públicos são, portanto, exemplos típicos de elementos do circuito inferior da economia urbana, como também, horizontalidades, contra racionalidades, formadas por uma solidariedade orgânica, de relações interna, velhas e de vizinhança e aproximação entre as pessoas. Porém, como os circuitos são indissociáveis, esses elementos do circuito inferior são apropriados e usados para a capilarização do circuito superior e consequentemente para a reprodução do capital.

Esses agentes do circuito inferior estão em constante conflito político, mediado pelo Estado, e ideológico, por intermédio da mídia. No conflito político, o Estado atende aos interesses dos agentes do circuito superior com investimentos em infraestrutura. Contraditoriamente, há um descaso desse mesmo Estado para com os elementos do circuito inferior, como as feiras livres e os mercados públicos, degradando-os e não dando o devido apoio de infraestrutura e de logística.

No conflito ideológico, há uma publicidade e propaganda enaltecendo os elementos do circuito superior, por exemplo, os supermercados, os hipermercados e os shoppings centers, que são demonstrados como elementos seguros, climatizados, e ambientalmente agradáveis. Enquanto essa mídia, por meio das redes de televisão e dos jornais impressos e via internet, propagam notícias que disseminam a ideia que os elementos do circuito inferior - feiras livres, mercados públicos, camelódromos - são inseguros, poluentes, insalubres e ambientalmente desagradáveis.

Assim, os supermercados e os hipermercados são elementos do circuito superior, como também, verticalidades, racionalidades, constituídas por uma solidariedade organizacional de relações externas, novas e de mercado. 0 Estado como vimos, nos exemplos anteriores, entra como um agente que atende aos interesses do circuito superior, por exemplo, através das centrais de abastecimento como a Ceasa-RN, que atende aos interesses do circuito superior. E, como os circuitos são indissociáveis, também atende, mesmo que de forma indireta aos interesses do circuito inferior.

Assim, as centrais de abastecimento, criadas pelo Estado, comportam-se como elementos mistos dos circuitos da economia urbana, sendo formadas pelo circuito superior e pelo circuito inferior. Nessa perspectiva, essas centrais são racionalidades paralelas, aconteceres homólogos e complementares para o circuito superior e para o circuito inferior.

Portanto, é no lugar, onde ocorrem as dialéticas do território usado e do espaço geográfico: circuito superior e circuito inferior, verticalidade e horizontalidades, solidariedade organizacional e solidariedade orgânica, racionalidade e contra racionalidade. Essa dialética expressa a simultaneidade das forças das re- des e das forças dos lugares no espaço. Essa dialética abre a possibilidade de um mundo diferente, um novo mundo, uma nova globalização, criada a partir dos agentes não hegemônicos, uma globalização diferente dessa fábula e da perversidade do mundo que vivenciamos.

Se o trabalho é a transformação do meio ecológico e do meio construído pelo ser humano, é através do trabalho desses agentes do circuito inferior que o mundo se transforma. Daí a necessidade de políticas públicas estatais que proporcione melhores condições ambientais de trabalho nas feiras livres, mercados públicos e centrais de abastecimento, fortalecendo o circuito inferior nos lugares.

O lugar é o cotidiano de cada indivíduo, de cada grupo social, de cada agente do espaço. Como também, o lugar é território usado e espaço geográfico. Este é formado por diversos territórios e por diferentes lugares. E o território, que também é espaço geográfico, constitui-se de vários lugares. Há, portanto, uma dialética das escalas (espaço geográfico, território usado e lugar), que é a dialética da totalidade (mundo, formação socioespacial e cotidiano).

\section{Considerações Finais}

A totalidade para a compreensão da realidade deve ser analisada, de acordo com a obra de Milton Santos, a partir de três escalas. A primeira escala é a totalidade mundo ou do modo de produção, o espaço geográfico. A segunda escala é a totalidade da formação socioespacial, o território usado. Por último, a terceira escala que se refere à totalidade do cotidiano, o lugar ou lugar-mundo.

O espaço geográfico é uma instância social formada por fixos e fluxos, configurações espaciais e dinâmicas sociais, sistemas de objetos e sistemas de ações, ou seja, sempre a relação entre o inerte e o dinâmico, o prático-inerte. 0 espaço geográfico, em sua totalidade, deve ser compreendido a partir das formas e dos conteúdos - estruturas, processos e funções. Como também essa totalidade é abarcada pelo processo de circulação - produção, distribuição, troca e consumo.

O espaço geográfico está relacionado com o território usado, assim como, o modo de produção está relacionado com a formação socioespacial. 0 território usado é, assim, a totalidade da formação socioespacial; a totalidade do Estado-nação. Este que é formado por um governo, um povo ou nação, uma soberania que se dá pela constituição, e pelo espaço geográfico, o território. Este é a forma, a configuração territorial - as infraestruturas (meio ecológico e meio construído) que é usada pela dinâmica territorial - os agentes (firmas, instituições e pessoas) externos e internos, novos e velhos, do mercado e do Estado.

O lugar é onde ocorre a dialética do território entre as redes e os lugares contíguos. Nos lugares também ocorre a dialética entre verticalidades e horizon- 
talidades, racionalidades e contra racionalidades, solidariedades organizacionais e solidariedades orgânicas, enfim, entre os agentes do circuito superior - com alto grau de tecnologia, capital e organização - e do circuito inferior - com um nível menor dessas variáveis.

Enfim, essa é sinteticamente a contribuição do geógrafo brasileiro Milton Santos, de forma geral para a teoria social crítica, e especificamente para a Geografia Crítica. $\mathrm{O}$ autor, como observado não se limitou ao materialismo histórico, sofrendo influências do estruturalismo e do existencialismo, focando no diálogo entre os pensamentos de Lefebvre, Althusser e Sartre.

Como também conseguiu fazer um diálogo entre as obras de Marx, Weber e Durkheim, que é considerado quase impossível pelas ciências sociais. Tal êxito do autor demonstra que em seu pensamento não havia uma preocupação em seguir uma corrente filosófica. Acima disso, Milton Santos procurou criar, produzir e desenvolver um método de análise geográfico tendo como base a dialética.

\section{Referências}

ALTHUSSER, Louis. Ideologia e aparelhos ideológicos de Estado. Lisboa: Presença, 1974.

CORRÊA, Roberto Lobato. Espaço: um conceito-chave da Geografia. CASTRO, Iná Elias de; GOMES, Paulo César da Costa; CORRÊA; Roberto Lobato. Geografia: conceitos e temas. Rio de Janeiro: Bertrand Brasil, 1995.

DURKHEIM, Émile. Da divisão do trabalho social. São Paulo: Abril Cultural, 1978 [1897].

HARVEY, David. A justiça social e a cidade. São Paulo: Hucitec, 1980.

LEFEBVRE, Henri. A produção do espaço. (Tradução não publicada). Belo Horizonte: UFMG, 2006 [1974].

MARX, Karl. Grundrisse. São Paulo: Boitempo, 2011 [1857].

RAFFESTIN, Claude. Por uma Geografia do poder. São Paulo: Ática, 1993.

SANTOS, Milton. Por uma Geografia Nova. São Paulo: Hucitec, 1978.

Da totalidade ao lugar. São Paulo: Edusp, 2005 [SANTOS, Milton. Espaço e sociedade. Petrópolis: Vozes, 1978]. $\overline{1979}$.

o espaço dividido. Rio de Janeiro: Francisco Alves,
. Espaço e método. São Paulo: Hucitec, 1985.

Circuitos espaciais de produção: um comentário. SOUZA, María Adélia de; SANTOS, Milton. A construção do espaço. São Paulo: Nobel, 1986.

Metamorfoses do espaço habitado. São Paulo: Hucitec, 1988.

O retorno do território. SANTOS, Milton; SOUZA, Maria Adélia; SILVEIRA, María Laura. Território: globalização e fragmentação. São Paulo: Hucitec, 1994.

A natureza do espaço. São Paulo: Hucitec, 1996.

Por uma outra globalização. Rio de Janeiro: Record, 2000.

; SILVEIRA, María Laura. O Brasil: território e sociedade no início do século XXI. Rio de Janeiro: Bertrand Brasil, 2001.

SARTRE, Jean-Paul. Crítica da razão dialética. Rio de Janeiro: DP\&A, 2002 [1960].

SOJA, Edward. Geografias pós-modernas: a reafirmação do espaço na teoria social crítica. Rio de Janeiro: Jorge Zahar, 1993.

SOUZA, Marcelo Lopes de. Os conceitos fundamentais da pesquisa sócio-espacial. Rio de Janeiro: Bertrand Brasil, 2013.

QUEIROZ, Thiago Augusto Nogueira de. As feiras livres de Natal-RN: um estudo a partir da teoria dos circuitos da economia urbana. Monografia de graduação (Geografia). Natal: UFRN, 2011b.

A Ceasa-RN e os circuitos da economia urbana: a circulação de hortifrutigranjeiros em Natal-RN. Dissertação de mestrado (Geografia). Natal: UFRN, 2014.

; AZEVEDO, Francisco Fransualdo de. Circuitos da economia urbana: arranjos espaciais e dinâmica das feiras livres em Natal-RN. Sociedade e território, Natal, v.24, n.1, p.115-133, jan./jun. 2012.

; AZEVEDO, Francisco Fransualdo de. As feiras livres e suas (contra) racionalidades: periodização e tendências a partir de Natal-RN-Brasil. Biblio 3W. Revista Bibliográfica de Geografía y Ciencias Sociales, Barcelona, Vol. XVIII, no 1009, 15 de enero de 2013.

TUAN, Yi Fu. Espaço e lugar. Rio de Janeiro: Difel, 1983.

WEBER, Max. Economia e sociedade. Brasília: Editora da UNB, 1991 [1920].

\section{GEOGRAPHICAL SPACE, USED TERRITORY AND PLACE: ESSAY ABOUT THE THOU- GHT OF MILTON SANTOS}

\footnotetext{
Abstract: This article results from discussions occurring within the discipline of Human Geography as studied in the History course. Space is not the key concept in all trends of geographical thought. Traditional Geography, influenced by positivism, historicism and Neo-Kantianism, has territory, landscape and region as its main con-
} 
cepts. On the other hand, Humanistic Geography, based on existentialism, focuses on the concept of place, understood as lived space. Quantitative Geography, influenced by neo-positivism, and Critical Geography, based on historical materialism, on their turn, emphasize the idea of space. The first theoretical standpoint understands space ideally, whereas the second sees space in its materiality, with objectivations and subjectivities. The Brazilian geographer Milton Santos, influenced by historical materialism, structuralism and existentialism, played an important role in Critical Geography. From this perspective, this article discusses the contribution of the thought and work of Milton Santos for Critical Geography and critical social theory, focusing on the concepts of geographical space, used territory and place, which are the three conceptual scales for understanding socio-spatial totality. With this objective, a literature review comprising works by and about the author was performed. For Milton Santos, "space" is a social instance, as well as politics, economy, and culture. In the current historical period, space is characterized by the materialization of the technical-scientific-informational environment, which is the geographical expression of globalization. Thus, this concept should be analyzed based on three scales of totality: the world, the socio-spatial formation and the quotidian. Geographical space formed by systems of objects (fixed and spatial configurations) and systems of actions (flows and social dynamics) constitute the totality of the world. Geographical space is, therefore, made by forms (spaces of production, distribution, exchange, consumption, and circulation) and contents (structures, processes, and functions). The totality of socio-spatial formation is the territory used, comprising the territorial configuration (infrastructures and the ecological environment) and territorial dynamics (use of the territory by the agents - companies, institutions and individuals). It is in the use of the territory by different agents that the dialectic between the external and the internal, the new and the old, the State and the market takes place. Finally, the author highlights the totality of place, the geographical dimension of everyday life that contains the dialectic between the upper circuit and the lower circuit, verticality and horizontality, rationalities and counter-rationalities, organizational solidarity and organic solidarity. Place is, in this sense, the strength to face globalization as fable and perversity, produced by networks; and to build globalization as a possibility.

Keywords: Geographical space, used territory, place, all, Milton Santos.

\title{
ESPACIO GEOGRÁFICO, TERRITORIO USADO Y LUGAR: ENSAYO SOBRE EL PENSA- MIENTO DE MILTON SANTOS
}

\begin{abstract}
Resumen: Este artículo se originó a partir de los debates que se plantearon en la asignatura Geografía Humana, que se impartió en la carrera de Historia. El espacio no es el concepto clave en todas las corrientes del pensamiento geográfico. La corriente de la Geografía Tradicional, influida por el positivismo, el historicismo y el neokantismo, toma el territorio, el paisaje y la región como principales conceptos. La corriente de la Geografía Humanística, basada en el existencialismo, se centra en el concepto de lugar, entendido como un espacio vivido. Las corrientes que toman el espacio como palabra clave son la Geografía Cuantitativa, con influencias del neopositivismo, y la Geografía Crítica, basada en el materialismo histórico. En la primera corriente, el espacio es comprendido de forma ideal, mientras que, en la segunda, el espacio se entiende en su materialidad, con objetivaciones y subjetivaciones. La corriente crítica recibió un importante aporte del geógrafo brasileño Milton Santos, influenciado por el materialismo histórico, el estructuralismo y el existencialismo. Desde esa perspectiva, este artículo tiene como objetivo mostrar la contribución del pensamiento y de la obra del geógrafo Milton Santos para la Geografía Crítica y para la teoría social crítica, centrándose en los conceptos de espacio geográfico, territorio usado y el lugar, que son las tres escalas conceptuales para entender la totalidad socioespacial. Para ello, se realizó una revisión bibliográfica del autor, y sobre el autor, que comprendió sus obras más importantes. Para este autor, el espacio es una instancia social, así como la política, la economía y la cultura. El espacio, en el período histórico actual, se caracteriza por la materialización del medio técnico-científico-informacional, expresión geográfica de la globalización. Por lo tanto, ese concepto se debe analizar desde tres escalas de la totalidad: el mundo, la formación socioespacial y la cotidianeidad. La totalidad mundo es el espacio geográfico formado por sistemas de objetos (fijos y configuraciones espaciales) y sistemas de acciones (flujos y dinámicas sociales). Por lo tanto, el espacio geográfico se compone de formas (espacios de producción, distribución, intercambio, consumo, circulación) y por contenidos (estructuras, procesos y funciones). La totalidad de la formación socioespacial es el territorio usado, que comprende la configuración territorial (las infraestructuras y el medio ecológico) y la dinámica territorial (uso del territorio por parte de los agentes, como empresas, instituciones y personas). Es en el uso del territorio por parte de los diferentes agentes que se produce la dialéctica entre lo externo y lo interno, lo nuevo y lo viejo, la Estado y el mercado. Por último, el autor destaca la totalidad del lugar, la dimensión geográfica de la vida cotidiana, donde se da la dialéctica entre el circuito superior y el circuito inferior, verticalidades y horizontalidades, racionalidades y contrarracionalidades, solidaridad organizacional y la solidaridad orgánica. El lugar es, en ese sentido, la fuerza para enfrentar la globalización como fábula y perversidad, producida por las redes; y construir una globalización como posibilidad.
\end{abstract}

Palabras clave: Espacio geográfico, territorio usado, lugar, total, Milton Santos. 